\title{
Research on frame system for sustainable development of rural construction in cold regions based on green concept
}

\author{
Tao Wang ${ }^{*}$ and Wen Cheng \\ Harbin Institute of Technology, Harbin, China
}

\begin{abstract}
With the rich connotations, the green concept has been widely applied to various fields, and gradually becomes an important thought of sustainable development. This paper analyzes the existing term related to green concept, studies the development and application of the green concept in recent ten years, and sums up the mainly connotations and future development directions of the green concepts. Based on green perspective, the paper analyses the realistic problems in the sustainable development of rural construction in cold regions. Combined with the green concept's connotation and the standard and target of the existing index system, the paper puts forward the main strategic system framework for the sustainable development of rural construction in cold regions, including five aspects: space resource system, green industry system, human and social organization system, ecological system and network engineering system. This paper hopes to provide the reference for the construction and development of village and town in cold regions.
\end{abstract}

\section{Introduction}

The green development concept has aroused high attention of political circles, educational circles, the public and business circles in various countries and gradually become a world trend with significant global climate change, increasingly exhausted resources and increasingly aggravating environment in recent years. The way of green development is imperative in both developed and backward regions, urban and rural regions in the world. The rapid development and extensive development mode in the cold northeast region of China have produced serious influence on rural ecological environment. Ecological unbalance, land degradation, excessive emission of rural pollutants and the sharp decrease of biological diversity have become "non-green" problems to be solved in the development and construction of villages and towns. How to achieve sustainable development of the construction of villages and towns in severe cold areas under green concept is an important and urgent task.

\section{2 "Green" basic concept for the construction of villages and towns}

\subsection{Interpretations of connotations of "green" concept}

Currently, the word "green" has been widely used in various fields and become a fashion, feature and trend. There are many terms and concepts combined with

\footnotetext{
* e-mail: wt706@163.com
}

"green" and widely spread and cognized, such as green economy, green building, green transport and green consumption. However, "green" has different connotations in different fields and phenomena.

Over 50 terms related to "green" are organized through integrated search on various life and academic websites. This paper further analyzes and explains them and digs different connotations of "green". The main constituent relation diagram of "green" connotations is formed through classification and sorting. The results show that connotations of "green" concept mainly include environmental protection, resource conservation, natural ecology, energy saving and emission reduction, high efficiency, sustainability, health and harmony, etc., which have been widely used in various regions such as economy, society, culture and environment. In terms of the original meaning of "green", its connotations can be divided into basic connotations and extended connotations. Basic connotations refer to natural color, plant and life and the symbol of vigor. Extended connotations refer to sustainability, high efficiency, energy saving and emission reduction etc. More different green connotations will form in allusion to different subsystems and factors in the sustainable development of construction of villages and towns.

\subsection{Application and development of "green" concept}

"Green" concept originates from green economy in the Economic Blue Book published in 1980. China first put forward the concept in 2002. The period from 2004 to 
2008 was the early stage of development and discussions have been conducted gradually in each field. Since 2009, green concept has risen rapidly and relevant conferences and workshops have been conducted widely. In 2012, it was included in the national 12th Five-Year Plan. With the promotion of national new urbanization, green concept has been gradually applied in urban and rural planning and construction. Over the last decade, China has held hundreds of relevant forums and research reports.

Currently, different "green" standards, indicators and evaluation systems have gradually formed in different fields, mainly focusing on social development, economic region, engineering construction and agricultural production etc. The constitution and standard of these indicator systems lay a foundation for the direction and objective of green and sustainable development of the construction of villages and towns in severe cold areas and expand the way of thinking.

\section{3 "Non-green" dilemma faced by sustainable development of the construction of villages and towns in severe cold areas}

\subsection{Continuous deterioration of ecological environment}

Ecological matrix space is faced with the severe challenge of agricultural production pollution in the scope of villages and towns. As agricultural production is extensive and simple in villages and towns and the circular dependency on chemical fertilizer, pesticide and mulching film is increasingly severe for the purpose of improving the output and saving physical strength and time, the use volume of pesticide, chemical fertilizer and mulching film in villages and towns in northeastern severe cold areas has increased greatly by $1.5-2.0$ times. In the scope of built-up areas in villages and towns, the pollution caused by sanitary sewage and waste, straw burning and winter heating is severe and the ecological living environment has deteriorated continuously due to the lack of infrastructure and weak environmental awareness of residents. In most villages and towns under investigation, wastewater is discharged randomly and garbage is stacked around houses and beside pits, roads, water source, spillways and ponds. Nobody is responsible for garbage collection and treatment. In addition, people and domestic animals live together in the courtyard residence in most villages. Such poor sanitary condition will easily cause epidemic situation and impose threat to the health of peasants [1].

\subsection{Extensive waste of land use}

Waste and inefficient use of land resources generally exist in villages and towns in severe cold areas. In terms of construction land per capita, the area of construction land per capita in towns under investigation is mainly $150-300 \mathrm{~m}^{2} /$ person and the average value is $234 \mathrm{~m}^{2} /$ person, far beyond the national standard $140 \mathrm{~m}^{2} /$ person; the area of construction land per capita in villages under investigation is generally too large, $80 \%$ of which is $170-350 \mathrm{~m}^{2} /$ person; it is even up to $667 \mathrm{~m}^{2} /$ person in some villages. The scale of homestead per household is also too large. On the national level, Heilongjiang Province, Jilin Province, Liaoning Province and Inner Mongolia Autonomous Region in northeastern severe cold areas are among provinces with the scale of homestead per household ranking the top six [2]. The sampling survey on peasant households in severe cold areas shows that the scale of their homesteads is generally too large. Compared to the standard $200-400 \mathrm{~m}^{2}$ specified by the province, about $77 \%$ homesteads of peasant households exceed the upper limit value and the average value is $592.73 \mathrm{~m}^{2}$. The scale of homesteads of some peasant households is up to over $2000 \mathrm{~m}^{2}$. There is a high potential for intensive tightening.

\subsection{Lack of public service and infrastructure}

The supply of public service and infrastructure is generally inadequate in villages and towns in severe cold areas. The proportion of public facility land in 50\% towns under investigation is $10-18 \%$ lower than the national standard rate. Moreover, the configuration and establishment of various public facilities have an unbalanced structure; administrative management land is adequate and recreational and sports facilities are lacking; there are few social welfare facilities such as nursing home. Due to scattered layout of villages, public facilities of compulsory education and primary-level culture and sports have a low coverage rate. In most villages and towns under investigation, the infrastructure is lacking, its land occupation proportion is mostly $0.5-1.0 \%$ and infrastructure land use per capita is only $1.5 \mathrm{~m}^{2} /$ person; garbage and waste water treatment facilities are not supplied in all villages and towns under investigation. Though water and heat supply facilities are provided, the quantity is inadequate. In addition, in terms of public service and infrastructure in severe cold areas, importance is often only attached to initial construction and future use management and maintenance are often neglected, thus causing low use efficiency and short service cycle.

\subsection{Backward building energy-saving technology}

Building energy-saving technology is backward in villages and towns in severe cold areas and the thermal performance of building envelope is still at a low level. Building walls are mostly brick-concrete structure and materials are mostly solid clay bricks with a thickness of $370 \mathrm{~mm}$. Sun-dried mud brick wall still exists in some villages, with a thickness of $300-900 \mathrm{~mm}$. In terms of heat insulation measures, roof insulation is most commonly used with a proportion of $60-80 \%$. Materials are mostly slag, polystyrene board, perlite, straw plate, crop straw, rice husk and saw dust. Wall insulation follows with a proportion of $20-40 \%$ and the material is mostly polystyrene foam plastic board. Ground insulation is weakest with a proportion of below $5 \%$. There are a high proportion of house doors and windows with single layer and without 
insulation measure. Windows hold a large proportion of the wall. It can reach about $55 \%$ on the south side and $40 \%$ on the north side.

\subsection{Progressive increase of traditional energy consumption and lack of new energy utilization}

Heating means in villages and towns in severe cold areas are mainly fire pit, burner and heating stove. Heating fuels are mostly coal, straw and electricity and domestic fuels are mostly gas tank, electric appliance and straw. The consumption of traditional energies such as electricity and coal is large. The annual coal consumption is about 3-5 t/household. Electric charges are 500-1000 Yuan/ household and electricity consumption has increased year by year. Rural electricity consumption in three major provinces in severe cold areas has increased by 2-3 times over the last decade. The widespread use ratio of new energy is low in villages and towns in severe cold areas. Solar water heater or solar house is used in only a few villages and towns. Renewable energies such as geothermal energy, biomass energy, compressed straw, marsh gas, small wind energy and small hydro are hardly used.

\section{Framework establishment of sustainable development of construction of villages and towns in severe cold areas under "green" concept}

The sustainable development of construction of villages and towns under green concept is an effective measure taken for current problems in land, energy and environment as well as a development mode giving consideration to sustainability, low carbon and emission reduction and the development of society, economy, resource and environment in villages and towns and paying attention to social-economic-natural compound ecological overall efficiency. The sustainable development of construction of villages and towns under green concept highlights low carbon, ecology and green in technology, integrates dialectical view, adaptation and defense in climatic conditions, pays attention to economical, intensive and tense utilization in land, guarantees adequate supply and balanced structure of public and basic services in facility and emphasizes the promotion of green technology and new energies matching with regional features in energy utilization.

The framework system for the sustainable development of construction of villages and towns in severe cold areas is established from the perspective of system theory according to connotation requirements of green concept and the standard of relevant indicators and quantitative system with climatic adaptation, eco-fitness, low carbon and environmental protection, health and harmony and economic development as basic objectives, including space resource system, green industry system, human and social organization system, ecological system and network engineering system which involve 26 submodules.
Space resource system: According to features of rural production mode and life pattern, it studies the utilization model of rural land space with sustainable development and conducts distribution guidance and control over land, culture and historical resources in villages and towns, including submodules such as village and town land use, village and town space control, historical culture and resource protection and water resource utilization.

Green industry system: From the perspective of the combination of institutional innovation and technical innovation, it focuses on discussing the feasible path for the sustainable development of villages and towns in severe cold areas from the perspective of economic operation and industrial development pattern, including submodules such as sustainable economic development strategies, industrial structure and layout system, green agricultural production technology system, green agricultural operating service system, green enterprise system and economic structure.

Human and social organization system: It comprehensively considers dynamic change features of population, settlement distribution in villages and towns, and social service and management guarantee system, including submodules such as village and town settlement system, green public service system, population and manpower employment system, service management system, social guarantee system and organization structural system.

Ecological environment system: It maintains and improves the ecological environmental quality with sustainable development in rural areas through the research on ecologically sensitive factors such as green ecological space, environmental pollution, climatic conditions and natural disasters, including submodules such as green network pattern system, environmental pollution and governance system, climate and disaster response system, natural ecological protection system and waste management and utilization system.

Network and engineering system: It focuses on studying green and low-carbon construction of engineering infrastructure, traffic system and logistics storage system in villages and towns and discussing how to make full use of rural biomass resources in the scope allowed by economy and transform them into high-grade energies and how to use local materials as raw materials of rural building, including submodules such as ecological infrastructure system, green traffic and logistics system, green energy supply and communication system, prevention and reduction of disasters and green building and courtyard system.

\section{Conclusions}

Many "non-green" problems are encountered in the construction of villages and towns in northeastern severe cold areas, which seriously restrain the sustainable development progress of villages and towns. It is required to start from connotation requirements of green concept 
and the standard of relevant indicators and quantitative system and establish the framework system for the sustainable development of construction of villages and towns in severe cold areas with climatic adaptation, ecofitness, low carbon, health and harmony and economic development as basic objectives so as to make contributions to the construction of beautiful rural areas and joint construction of harmonious China.

\section{References}

1. S. Aiyun, S. Yanming, F. Ming, Z. Hui, Compilation principle of the technical guidance for village redevelopment, City Plan. Rev. 8, 64 (2006)

2. S. Wei, C. Baiming, Y. Hong, C. Xi, et al., Analysis on the status quo of residence base resources in rural areas of China, Chin. J. Agric. Resour. Reg. Plan. 6, 1 (2008)

Cite this article as: Tao Wang, Wen Cheng, Research on frame system for sustainable development of rural construction in cold regions based on green concept, Renew. Energy Environ. Sustain. 1, 19 (2016) 